EXTENDED REPORT

\title{
Increased pentosidine, an advanced glycation end product, in serum and synovial fluid from patients with knee osteoarthritis and its relation with cartilage oligomeric matrix protein
}

\author{
L Šenolt, M Braun, M Olejárová, š Forejtová, J Gatterová, K Pavelka
}

Ann Rheum Dis 2005;64:886-890. doi: 10.1136/ard.2004.029140

See end of article for authors' affiliations

Correspondence to:

Professor K Pavelka, Institute of Rheumatology, Na Slupi 4, 12850 Prague

2, Czech Republic; pavelka@revma.cz

Accepted

21 November 2004

\begin{abstract}
Background: Pentosidine, an advanced glycation end product, increasingly accumulates in articular cartilage with age, and contributes to the pathogenesis of osteoarthritis (OA). Increased pentosidine concentrations are associated with inflammatory disorders - for example, rheumatoid arthritis.

Objective: To compare pentosidine serum concentrations in patients with knee OA and in healthy volunteers and to determine a relationship between pentosidine and cartilage oligomeric matrix protein (COMP) - a marker of articular cartilage destruction.

Methods: Paired serum and synovial fluid samples were obtained by arthrocentesis from 38 patients with knee OA and from 38 healthy volunteers. Pentosidine concentration was measured by reverse phase high performance liquid chromatography with fluorescent detection and COMP was determined by sandwich ELISA.

Results: Significantly increased serum pentosidine $(p<0.01)$ and COMP $(p<0.05)$ levels were detected in the patients with $O A$ compared with the control group. Serum pentosidine correlated significantly with synovial fluid pentosidine $(p<0.001)$. Pentosidine in synovial fluid $(p<0.05)$ and in serum $(p<0.05)$ correlated significantly with synovial fluid COMP. Pentosidine and COMP concentrations did not correlate significantly with the radiological stage of the disease.

Conclusion: Increased pentosidine serum concentration in patients with OA and its correlation with the cartilage destruction marker COMP in synovial fluid suggests that pentosidine may be important in OA pathology and is a new potential OA marker.
\end{abstract}

O steoarthritis (OA) is a multifactorial, structurally complex condition affecting the entire joint. At the molecular level, OA is characterised by an imbalance between the synthesis of cytokines, metalloproteinases, and their natural inhibitors. ${ }^{1}$ These changes finally lead to articular cartilage destruction, and changes in the subchondral bone and synovial membrane. Almost 15\% of the adult population is affected by OA, which often results in impaired joint motion, pain, and disability. ${ }^{2}$ Age has been identified as an important risk factor for the development of OA. ${ }^{3}$ In the course of aging, advanced glycation end products (AGE), resulting from non-enzymatic glycation, accumulate in numerous body tissues. The carbonyl group of sugars is condensed with modified protein amino acids and is significantly accelerated by oxidative stress. ${ }^{4}$

Articular cartilage is predominantly made up of molecules with a long biological half life, which compared with other tissues, makes it more sensitive to increased AGE accumulation, ${ }^{45}$ Recent works by Verzijl, DeGroot et al showed a relationship between increased AGE accumulation and the alteration of the molecular, biochemical, and biophysical properties of the articular cartilage, which may be more prone to damage and thus OA development. ${ }^{5-9}$

Pentosidine is a highly sensitive marker for all AGE. ${ }^{4}$ Serum levels of this so-called senescence cross link were found to be raised in patients with diabetes mellitus ${ }^{10}$ and renal disorders. ${ }^{11}$ Takahashi et al observed a significantly higher pentosidine concentration in articular cartilage in patients with rheumatoid arthritis (RA) than in a control group and in patients with OA. ${ }^{12}$ This was explained by the presence of increased oxidative stress during chronic inflammation. Further research showed a correlation between increased pentosidine levels in body fluids and RA activity, making pentosidine a potential new RA biomarker. ${ }^{12-15}$

Pentosidine in RA and OA has been shown to correlate significantly with disease activity in serum/plasma and synovial fluid, although its level was significantly higher in RA than in OA. ${ }^{14}$ In addition to other inflammatory markers such as $\mathrm{C}$ reactive protein, erythrocyte sedimentation rate, and white blood cell or platelet count, plasma pentosidine in patients with RA also correlated with matrix metalloproteinase-3, an important degradative enzyme in the cartilage breakdown. ${ }^{15}$ Nevertheless, there is a lack of papers dealing with body fluid levels of pentosidine and its consequences in OA. DeGroot et al detected higher urine pentosidine levels in patients with OA than in controls and calculated a predictive quotient using pentosidine to determine the presence of OA. ${ }^{9}$ Moreover, we have recently documented an increase in the pentosidine concentration in serum from patients with OA, with pentosidine being a predictive marker of further disease progression. ${ }^{16}$

In this cross sectional study, we compared pentosidine levels in patients with primary knee joint OA with levels in control subjects. Because articular cartilage degradation during OA is linked to the loss of AGE fluorescence near to the cartilage surface, ${ }^{17}$ a comparison was made between pentosidine and a marker of articular cartilage destructioncartilage oligomeric matrix protein (COMP)..$^{19}$

Abbreviations: AGE, advanced glycation end product(s); ANOVA, analysis of variance; $C O M P$, cartilage oligomeric matrix protein; $O A$, osteoarthritis; RA, rheumatoid arthritis 


\begin{tabular}{|c|c|c|c|}
\hline Characteristic & $\begin{array}{l}\text { OA } \\
(n=38)\end{array}$ & $\begin{array}{l}\text { Controls } \\
(n=38)\end{array}$ & p Value \\
\hline Age (years) & $64.1(10.1)$ & $58.3(9.1)$ & $<0.05$ \\
\hline $\operatorname{Sex}(M / F)$ & $13 / 25$ & $15 / 23$ & NS \\
\hline \multicolumn{4}{|l|}{ OA grade $(\mathrm{K}-\mathrm{L})$} \\
\hline I & 2 & & \\
\hline ॥ & 18 & & \\
\hline III & 14 & & \\
\hline IV & 4 & & \\
\hline $\begin{array}{l}x \text { Ray imaging } \\
\text { reasons, not pe } \\
\text { K-L, Kellgren-La }\end{array}$ & $\begin{array}{l}\text { e knee joint } \\
\text { ned. } \\
\text { nce. }\end{array}$ & & \\
\hline
\end{tabular}

\section{PATIENTS AND METHODS Patients}

Of the 50 patients fulfilling the American College of Rheumatology criteria for clinical and radiological diagnosis of knee $\mathrm{OA}^{20} 12$ patients were excluded because they had abnormal serum levels of creatinine, a history of renal disease, and diabetes mellitus, which might have had a false positive influence on pentosidine levels. ${ }^{10} 11$ The remaining 38 subjects were included in the final evaluation. Outpatients from the Institute of Rheumatology (Prague, Czech Republic) undergoing therapeutic arthrocentesis were asked to participate. Blood was collected from those subjects who agreed and gave written informed consent; all of which was approved by the local ethics committee.

The control group comprised 38 volunteers employed in the institute without clinically manifested OA of the knee or other joints, diabetes mellitus, abnormal serum creatinine, or renal disorder. However, for ethical reasons, no radiographs were obtained from the control group. Table 1 shows the basic characteristics of the patients and the control subjects.

\section{Radiological and biochemical examination}

For radiological examination, the knee was placed in full extension in order to achieve maximum standardisation, as we described previously. ${ }^{21}$ The $x$ ray cassette film was placed $1.15 \mathrm{~m}$ from the tube and anteroposterior weightbearing radiographs were obtained with the patients' heels and toes together and fully extended. The radiographs were evaluated by the Kellgren-Lawrence grading scale and were assessed by two skilled radiologists. The knee joint which was the most swollen and painful was selected.

Collected blood serum and synovial fluid were stored at $-70^{\circ} \mathrm{C}$ until needed for analysis. Pentosidine in the serum and synovial fluid was analysed by high performance liquid chromatography ${ }^{22}$ and COMP levels were determined by a sandwich enzyme linked immunosorbent assay (ELISA) technique using monoclonal antibodies $17-\mathrm{C} 10$ and 16F12. ${ }^{23}$ Both methods have been described in detail in our previous publications. ${ }^{22} 23$
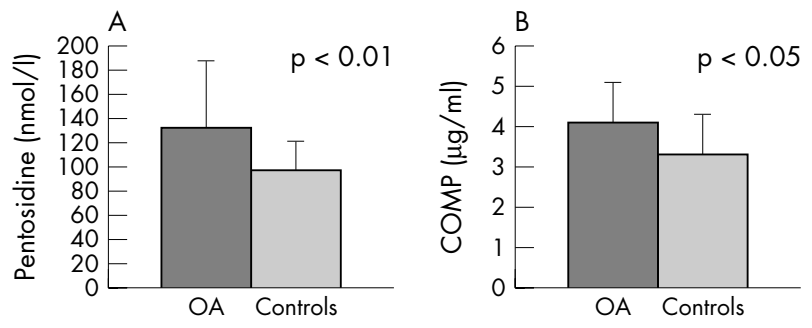

Figure 1 Comparison of the serum levels of $(A)$ pentosidine and (B) COMP in patients with OA and in controls.

\section{Statistical analysis}

All values were presented as mean and standard deviation (SD). During statistical analysis, a linear regression method analysing the relationship between two variables was used; statistical significance of the correlation was determined by Spearman's coefficient. Student's $t$ test was used to evaluate significance between the two groups. Analysis of variance (ANOVA) was used to determine the relation between biomarkers and radiological findings. Values of $\mathrm{p}<0.05$ were considered significant.

\section{RESULTS}

After exclusion of people with diabetes mellitus and renal insufficiency 38 patients with OA-25 women and 13 men, aged 46-79 years (mean (SD) 64.1 (10.1))-were enrolled in the cross sectional study for final evaluation. The control group comprised 38 subjects-23 women and 15 men aged 40-80 years (mean (SD) $58.3(9.1)$ ).

\section{Biochemical variables and their correlation}

Compared with the control group, significantly higher mean (SD) serum pentosidine (132.1 (56.2) v 97.7 (24.0) nmol/l, $\mathrm{p}<0.01)$ and COMP (4.1 (1.3) $v 3.3(1.4) \mu \mathrm{g} / \mathrm{ml}, \mathrm{p}<0.05)$ levels were found in the patients with OA (fig 1). In agreement with previous studies, ${ }^{14}{ }^{15}$ we found a significant correlation between serum and synovial fluid levels of pentosidine $\left(r^{2}=0.5619, \mathrm{p}<0.001\right)$, but no correlation was seen between serum and synovial fluid COMP $\left(r^{2}=0.0053\right)$ (fig 2). In addition, a significant correlation between pentosidine and COMP in synovial fluid $\left(r^{2}=0.1107\right.$, $\mathrm{p}<0.05$ ) was found, and the same was true for serum pentosidine and synovial fluid COMP $\left(r^{2}=0.1167, \mathrm{p}<0.05\right)$ (fig 3). Pentosidine concentrations were significantly higher in serum than in synovial fluid (132.1 (56.2) $v 70.7$ (22.8) nmol/l, $\mathrm{p}<0.001$ ). COMP concentrations, on the other hand, were significantly higher in synovial fluid than in serum of patients with OA (33.7 (11.0) $v 4.1$ (1.3) $\mu \mathrm{g} / \mathrm{ml}$, $\mathrm{p}<0.001$ ) (fig 4 ). No correlation between serum COMP and serum pentosidine $\left(\mathrm{r}^{2}=0.0092\right)$ or synovial fluid pentosidine $\left(\mathrm{r}^{2}=0.0214\right)$ was determined. Table 2 shows all the results obtained.

The average age of the patients with OA was higher than that of the controls (64.1 $v 58.3$ years, $\mathrm{p}<0.05$ ), but no relation was found between serum pentosidine levels and the age of patients with OA $\left(r^{2}=0.0013\right)$ and that of the controls $\left(r^{2}=-0.0017\right)$. However, a correlation between serum COMP concentrations in both the patients with OA $\left(\mathrm{r}^{2}=0.1859\right)$ and the controls $\left(r^{2}=0.1918\right)$ and their age was demonstrated. On the other hand, synovial fluid concentrations of COMP did not correlate with the age of patients with OA $\left(r^{2}=0.0729\right)$.

\section{Relationship between the variables studied and the radiological stage of the disease}

In the group studied more patients had bilateral knee OA than unilateral affection of the joint (31:7). However, no significant differences were found between the measures studied and unilateral or bilateral knee OA (data not shown). Overall, more patients in the second and third stage of OA of the knee were enrolled into the study; the first stage was diagnosed only in two patients and the fourth stage only in four. ANOVA did not show any correlation between pentosidine and COMP in the serum and synovial fluid and the radiological stage of the disease (table 3 ).

\section{DISCUSSION}

In this cross sectional study, statistically significant increases in the concentrations of pentosidine and COMP in the serum of patients with knee OA were determined and compared 

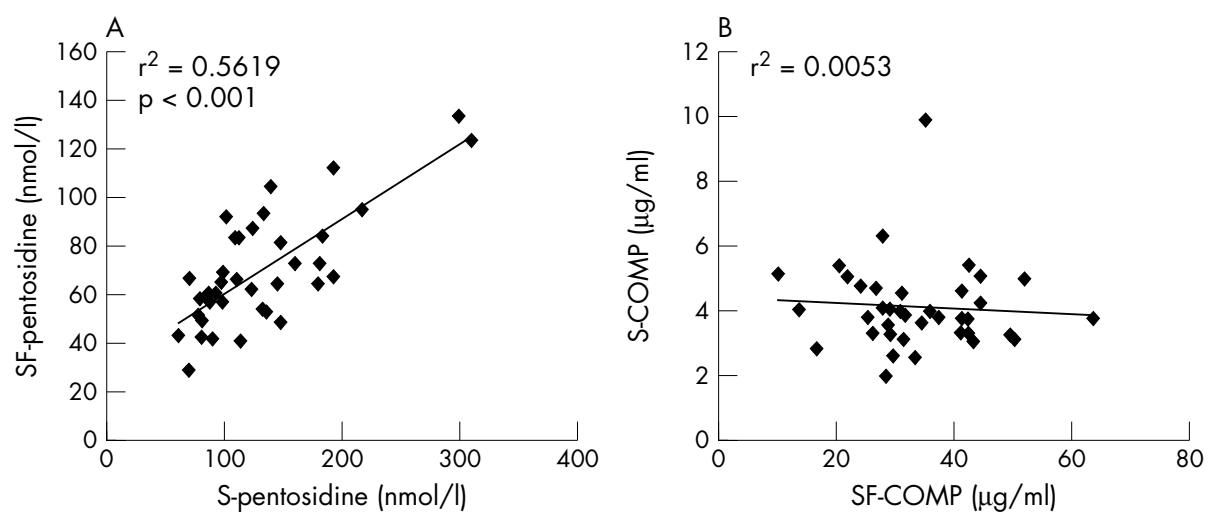

Figure 2 Correlation between serum (S) and synovial fluid (SF) levels of (A) pentosidine and (B) COMP in patients with OA.

with those in a control group of healthy volunteers. In patients with OA a significant correlation between synovial fluid pentosidine and COMP was found, and between serum pentosidine and synovial fluid COMP.

Miyata et al did not find a statistically significant increase of plasma pentosidine in patients with OA compared with controls, ${ }^{15}$ but we did detect a significantly raised serum pentosidine concentration in a greater number of patients with OA in this study. Our finding is in agreement with a recent observation of increased serum pentosidine in patients with OA, where pentosidine even had a predictive value for further disease progression. ${ }^{17}$ Moreover, the increased urine pentosidine levels in patients with OA found by DeGroot et al were predictive of the presence of $\mathrm{OA}$ in a logistic regression model. ${ }^{9}$

The mechanism of these observations still remains to be explained. In our view the increased pentosidine concentration in patients with OA may be the result of at least two mechanisms: (a) higher metabolic turnover and progressive destruction of hyaline cartilage and $(b)$ oxidative stress. Increased metabolic turnover and progressive destruction of $\mathrm{OA}$ articular cartilage ${ }^{24}$ may lead to the observed loss of AGE fluorescence near to the cartilage surface $^{17}$ and to the expected release of pentosidine modified proteins into body fluids. Inflammation has been considered to be a part of OA in recent years ${ }^{25}$ and thus OA may also be accompanied by systemic inflammation of low activity expressed through slightly increased serum C reactive protein. ${ }^{26}{ }^{27}$ Mildly increased oxidative stress during OA may represent yet another mechanism leading to an increase in serum pentosidine in patients with OA. According to our unpublished observation, pentosidine is significantly higher in RA than in OA, which is in agreement with previously published studies. ${ }^{13}{ }^{14}$ The increase of pentosidine might be explained by increased oxidative stress during systemic inflammation in RA. Pentosidine is mostly catabolised in the kidney and renal disorders can cause retention of pentosidine in the blood circulation. $^{11}$ Another important factor leading to AGE formation and accumulation is chronic hyperglycaemia, the main pathophysiological feature of diabetes mellitus. Pentosidine was significantly raised in diabetic patients in contrast with normal subjects. ${ }^{10}{ }^{15}$ Nevertheless, no significant difference of plasma pentosidine in diabetic patients compared with patients with OA was found. ${ }^{15}$ It might be suggested that oxidative stress and joint destruction are as important in leading to an increase in pentosidine in normoglycaemic patients with OA as hyperglycaemia is in diabetic patients.

COMP is an important component of hyaline cartilage, as well as an indicator of its metabolism..$^{28}$ Some authors view it as a potential predictive measure of knee OA progression. ${ }^{29} 30$ COMP is produced both by chondrocytes and synovial fibroblasts ${ }^{31}$; however, it is considered to be an important indicator of cartilage destruction. ${ }^{18}{ }^{19}$ Pentosidine levels are, contrary to those of COMP, significantly higher in serum than in synovial fluid; serum pentosidine might therefore be an indicator of systemic disease rather than disease of local origin and might also reflect the chronic inflammatory process. When pentosidine levels in patients with RA were expressed per mg of protein the values were nearly three times higher in synovial fluid than in plasma. ${ }^{15}$ Pentosidine has a protein bound form and thus raised serum levels of pentosidine are derived particularly from the whole body rather than only from the synovial fluid. The concentration of
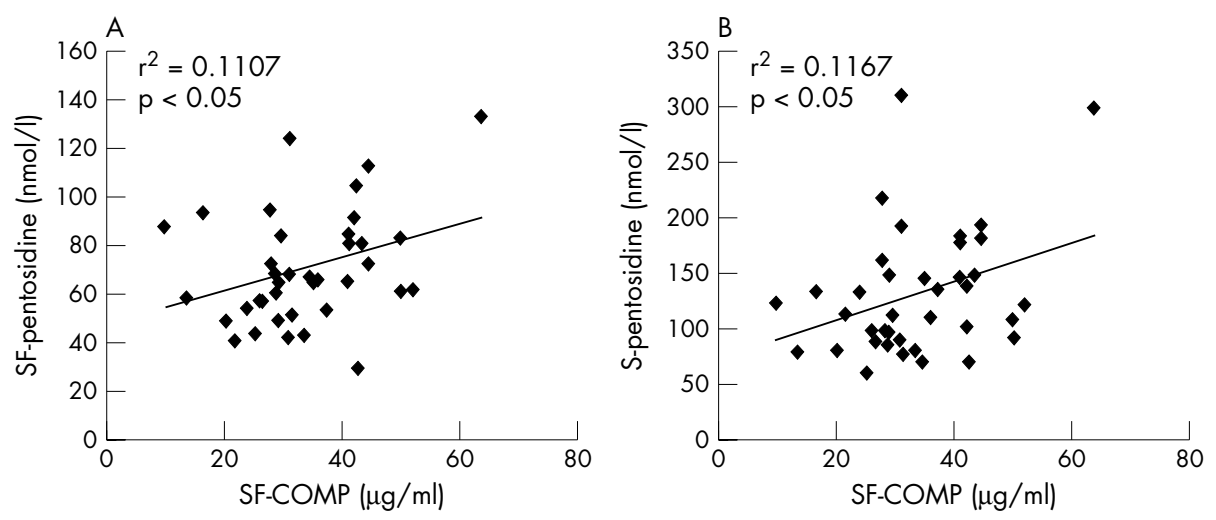

Figure 3 Correlation between (A) pentosidine and COMP in synovial fluid (SF) and (B) pentosidine in serum (S) and COMP in SF in patients with OA. 

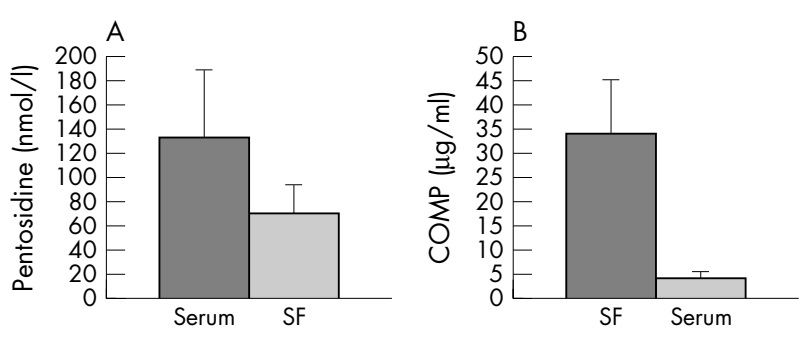

Figure 4 (A) Serum levels of pentosidine are significantly increased compared with levels in synovial fluid (SF) in patients with OA $(p<0.001)$. (B) In contrast, serum levels of COMP are significantly decreased compared with levels in SF in patients with OA $(p<0.001)$.

proteins is lower in synovial fluid than in serum and thus during local inflammation and joint destruction, pentosidine may be transferred into the synovial fluid via blood circulation. The correlation between COMP and pentosidine in synovial fluid might thus indicate an association between the slight chronic inflammation and cartilage destruction, making pentosidine a new potential marker of joint disease in patients with knee OA. One might speculate that patients with OA have a systemic form of the disease rather than only local problems.

Pentosidine and COMP levels, perhaps owing to the small number of patients with first and fourth grade OA, showed no significant correlation with the radiological status of the disease. However, we believe that serum concentrations of these variables may be more predictive in a dynamic pathological state, rather than radiographs that indirectly reflect a static long term process leading to cartilage loss. The drawback of the current study is its cross sectional character, the small number of patients with OA and absence of information about whether joints other than the knee joints might have OA. We evaluated the $x$ ray findings with the Kellgren-Lawrence grading scale; more sophisticated imagining methods such as measuring the joint space width using, for example, the atlas published by Altman et al, ${ }^{32}$ were not used For ethical reasons, no radiographs or synovial fluid samples were obtained from the control group subjects. In general, it might be suggested that the increasing serum level of COMP with age in patients with OA and controls reflects age related cartilage damage. On the other hand, the synovial fluid level of COMP is probably more related to the local joint degradation and is thus not influenced by age. Mean pentosidine and COMP levels were higher in patients with OA than in the control group. However, owing to a higher variance of these measures in the control group, these levels have no diagnostic significance for patients with OA. Nevertheless, both pentosidine and COMP are potential OA markers, which may have a prognostic value for development of the disease. ${ }^{16} 2930$

In conclusion, we confirmed that serum pentosidine concentrations are increased in patients with OA, which, in our recent work, was predictive of the narrowing of the joint space in OA of the knee joint. ${ }^{16}$ Moreover, the correlation between pentosidine and COMP in synovial fluid makes pentosidine a new potential biomarker of the OA process.

Table 2 Biochemical markers in 38 patients with knee OA and 38 controls

\begin{tabular}{|c|c|c|c|c|c|}
\hline \multirow[b]{2}{*}{ Marker } & \multicolumn{2}{|l|}{ OA } & \multirow[b]{2}{*}{ Control serum } & \multirow[b]{2}{*}{ pl } & \multirow[b]{2}{*}{ p2 } \\
\hline & Serum & SF & & & \\
\hline Pentosidine (nmol/l) & $132.1(56.2)$ & $70.7(22.8)$ & $97.7(24.1)$ & $<0.001$ & $<0.01$ \\
\hline $\operatorname{COMP}(\mu \mathrm{g} / \mathrm{ml})$ & $4.1(1.3)$ & $33.7(11.0)$ & $3.3(1.4)$ & $<0.001$ & $<0.05$ \\
\hline \multicolumn{6}{|c|}{$\begin{array}{l}\text { Results are shown as mean (SD). } \\
\text { COMP, cartilage oligomeric matrix protein; SF, synovial fluid. } \\
\text { pl, comparison of biochemical markers between serum and SF in patients with knee OA; } 2 \text {, comparison of serum } \\
\text { biochemical markers between patients with knee } \mathrm{OA} \text { and controls. }\end{array}$} \\
\hline
\end{tabular}

Table 3 Serum and synovial fluid pentosidine and COMP by radiographic findings according to Kellgren-Lawrence

\begin{tabular}{|c|c|c|c|c|c|}
\hline Marker & $\begin{array}{l}\text { OA grade } \\
(\mathrm{K}-\mathrm{L})\end{array}$ & $\mathbf{n}$ & Mean (SD) & ANOVA & p Value \\
\hline Pentosidine (S) & $\begin{array}{l}\text { I } \\
\text { II } \\
\text { III } \\
\text { IV }\end{array}$ & $\begin{array}{r}2 \\
18 \\
14 \\
4\end{array}$ & $\begin{array}{l}112.0(1.4) \\
123.2(57.7) \\
142.2(63.5) \\
147.0(46.4)\end{array}$ & 0.44 & 0.72 \\
\hline Pentosidine (SF) & $\begin{array}{l}\text { I } \\
\text { II } \\
\text { III } \\
\text { IV }\end{array}$ & $\begin{array}{r}2 \\
18 \\
14 \\
4\end{array}$ & $\begin{array}{l}75.0(12.5) \\
71.5(25.4) \\
70.1(24.9) \\
67.2(13.5)\end{array}$ & 0.06 & 0.98 \\
\hline COMP (S) & $\begin{array}{l}\text { I } \\
\text { II } \\
\text { III } \\
\text { IV }\end{array}$ & $\begin{array}{r}2 \\
18 \\
14 \\
4\end{array}$ & $\begin{array}{l}3.4(1.0) \\
3.9(0.8) \\
4.6(1.9) \\
4.4(1.0)\end{array}$ & 1.06 & 0.38 \\
\hline COMP (SF) & $\begin{array}{l}\text { I } \\
\text { II } \\
\text { III } \\
\text { IV }\end{array}$ & $\begin{array}{r}2 \\
18 \\
14 \\
4\end{array}$ & $\begin{array}{l}32.8(4.4) \\
33.8(10.4) \\
32.9(13.3) \\
36.7(11.0)\end{array}$ & 0.12 & 0.95 \\
\hline
\end{tabular}

Results are shown as mean (SD).

Analysis of variance (ANOVA) shows no differences in pentosidine or in COMP among the OA grades. COMP, cartilage oligomeric matrix protein; S, serum; SF, synovial fluid; K-L, Kellgren-Lawrence. 


\section{ACKNOWLEDGEMENTS}

The study was supported by a grant of the Czech Ministry of Health (MZCR) C. NK/5366-4.

\section{Authors' affiliations}

L Šenolt, M Braun, M Olejárová, š Forejtová, J Gatterová, K Pavelka Institute of Rheumatology, Prague and Clinic of Rheumatology, Charles University, 1 st Medical School, Prague, Czech Republic

\section{REFERENCES}

1 lannone F, Lapadula G. The pathophysiology of osteoarthritis. Aging Clin Exp Res 2003; 15:364-72.

2 Lawrence RC, Helmick GG, Arnett DF, et al. Estimates of the prevalence of arthritis and selected musculosceletal disorders in the United States. Arthritis Rheum 1998;41:778-788

3 Loeser RF Jr. Aging and the etiopathogenesis and treatment of osteoarthritis Rheum Dis Clin North Am 2000;26:547-67.

4 Sell DR, Monnier VM. Structure elucidation of a senescence cross-link from human extracellular matrix. Implication of pentoses in the aging process. $J$ Biol Chem 1989;264:21597-602.

5 Verziil N, DeGroot J, Oldehinkel E, Bank RA, Thorpe SR, Baynes JW, et al. Age-related accumulation of Maillard reaction products in human articular cartilage collagen. Biochem J 2000;350:381-387.

6 DeGroot J, Verziil N, Bank RA, Lafeber FPJG, Bijlsma JWJ, TeKoppele JM. Age-related decrease in proteoglycan synthesis of human articular chondrocytes. The Role of Nonenzymatic glycation. Arthritis Rheum 1999:42:1003-9.

7 DeGroot J, Verziil N, Wenting-Van Wijk MJG, Bank RA, Lafeber FPJG, Bijlsma JWJ, et al. Age-related decrease in susceptibility of human articular cartilage to matrix metalloproteinase-mediated degradation. The role of advanced glycation end products. Arthritis Rheum 2001:44:2562-71.

8 Verziil N, DeGroot J, Zaken ChB, Braun-Benjamin O, Maroudas A, Bank RA, et al. Crosslinking by advanced glycation end products increases the stiffness of the collagen network in human articular cartilage. A possible mechanism through which age is a risk factor for osteoarthritis. Arthritis Rheum 2002;46:114-123.

9 DeGroot J, Verziil N, Wenting-van Wiik MJ, Jacobs KM, Van El B, Van Roermund PM, Bank RA, Biilsma JW, TeKoppele JM, Lafeber FP. Accumulation of advanced glycation end products as a molecular mechanism for aging as a risk factor in osteoarthritis. Arthritis Rheum 2004;50:1207-15.

10 Sugiyama S, Miyata T, Ueda Y, Tanaka H, Maeda K, Kawashima S, et al. Plasma levels of pentosidine in diabetic patients: an advanced glycation end product. J Am Soc Nephrol 1998;9:1681-8.

11 Miyata M, lida Y, Horie K, Cai Z, Sugiyama S, Maeda K. Pathophysiology of advanced glycation end-products in renal failure. Nephrol Dial Transplant 1996:11:27-80.

12 Takahashi M, Kushida K, Ohishi T, Kawana K, Hoshino H, Uchiyama A, et al. Quantitative analysis of crosslinks pyridinoline and pentosidine in articular cartilage of patients with bone and joint disorders. Arthritis Rheum 1994:37:724-28.

13 Chen JR, Takahashi M, Suzuki M, Kushida K, Miyamoto S, Inove T. Pentosidine in synovial fluid in osteoarthritis and rheumatoid arthritis: relationship with disease activity in rheumatoid arthritis. J Rheumatol 1998;25:2440-4.

14 Chen JR, Takahashi M, Suzuki M, Kushida K, Miyamoto S, Inoue T. Comparison of the concentrations of pentosidine in the synovial fluid, serum and urine of patients with rheumatoid arthritis and osteoarthritis. Rheumatology (Oxford) 1999;38:1275-8.

15 Miyata T, Ishiguro N, Yasuda Y, Ito T, Nangaku M, Iwata H, et al. Increased pentosidine, an advanced glycation end product, in plasma and synovial fluid from patients with rheumatoid arthritis and its relation with inflammatory markers. Biochem Biophys Res Commun 1998;244:45-9.

16 Pavelka K, Forejtova S, Olejarova M, Gatterova J, Senolt L, Spacek P, et al. Hyaluronic acid levels may have predictive value for the progression of knee osteoarthritis. Osteoarthritis Cartilage 2004;12:277-83.

17 Gibson GJ, Verner JJ, Nelson FR, Lin DL. Degradation of the cartilage collagen matrix associated with changes in chondrocytes in osteoarthrosis. Assessment by loss of background fluorescence and immunodetection of matrix components. J Orthop Res 2001;19:33-42.

18 Larsson E, Erlandsson Harris H, Lorentzen JC, Larsson A, Mansson B, Klareskog $\mathrm{L}$, et al. Serum concentrations of cartilage oligomeric matrix protein, fibrinogen and hyaluronan distinguish inflammation and cartilage destruction in experimental arthritis in rats. Rheumatology (Oxford) 2002;41:996-1000

19 Neidhart M, Hauser N, Paulsson M, DiCesare PE, Michel BA, Hauselmann HJ. Small fragments of cartilage oligomeric matrix protein in synovial fluid and serum as markers for cartilage degradation. $\mathrm{Br} J$ Rheumatol 1997;36:1151-60.

20 Altman R, Asch E, Bloch D, Bole G, Borenstein D, Brandt K, et al. Development of criteria for the classification and reporting of osteoarthritis. Classification of osteoarthritis of the knee. Diagnostic and Therapeutic Criteria Committee of the American Rheumatism Association. Arthritis Rheum 1986;29:1039-49.

21 Pavelka K, Gatterova J, Gollerova V, Urbanova Z, Sedlackova M, Altman RD. A 5-year randomized controlled, double-blind study of glycosaminoglycan polysulphuric acid complex (Rumalon) as a structure modifying therapy in osteoarthritis of the hip and knee. Osteoarthritis Cartilage 2000;8:335-42.

22 Špaček P, Adam M. HPLC method for pentosidine determination in urine, serum, and tissues as a marker of glycation and oxidation loading of the organism. J Liq Chrom Rel Technol 2002;25:1807-20.

23 Vilím V, Voburka Z, Vytášek R, Šenolt L, Tchetverikov I, Kraus VB, et al. Monoclonal antibodies to human cartilage oligomeric matrix protein: epitope mapping and characterization of sandwich ELISA. Clin Chim Acta 2003;328:59-69.

24 Aigner T, McKenna L. Molecular pathology and pathobiology of osteoarthritic cartilage. Cell Mol Life Sci 2002;59:5-18.

25 Attur MG, Dave M, Akamatsu M, Katoh M, Amin AR. Osteoarthritis or osteoarthrosis: the definition of inflammation becomes a semantic issue in the genomic era of molecular medicine. Osteoarthritis Cartilage 2002;10:1-4.

26 Spector TD, Hart DJ, Nandra D, Doyle DV, Mackillop N, Gallimore JR, et al. Low-level increases in serum C-reactive protein are present in early osteoarthritis of the knee and predict progressive disease. Arthritis Rheum 1997:40:723-7.

27 Sturmer T, Brenner H, Koenig W, Gunther KP. Severity and extent of osteoarthritis and low grade systemic inflammation as assessed by high sensitivity C reactive protein. Ann Rheum Dis 2004;63:200-5.

28 Saxne T, Heinegard D. Cartilage oligomeric matrix protein: a novel marker of cartilage turnover detectable in synovial fluid and blood. $\mathrm{Br} J$ Rheumatol 1992;31:583-91

29 Vilím V, Olejárová M, Macháček S, Gatterová J, Kraus VB, Pavelka K. Serum levels of cartilage oligomeric matrix protein (COMP) correlate with radiographic progression of knee osteoarthritis. Osteoarthritis Cartilage 2002; 10:707-13

30 Sharif M, Saxne T, Shepstone L, Kirwan JR, Elson CJ, Heinegard D, et al. Relationship between serum cartilage oligomeric matrix protein levels and disease progression in osteoarthritis of the knee joint. $\mathrm{Br} J$ Rheumatol 1995;34:306-10

31 Hummel KM, Neidhart M, Vilim V, Hauser N, Aicher WK, Gay RE, et al. Analysis of cartilage oligomeric matrix protein (COMP) in synovial fibroblasts and synovial fluids. $\mathrm{Br} J$ Rheumatol 1998;37:721-8.

32 Altman RD, Hochberg M, Murphy WA Jr, Wolfe F, Lequesne M. Atlas of individual radiographic features in osteoarthritis. Osteoarthritis Cartilage 1995;3(Suppl A):3-70. 